\title{
Alternatives to In Vivo Draize Rabbit Eye and Skin Irritation Tests with a Focus on 3D Reconstructed Human Cornea-Like Epithelium and Epidermis Models
}

\author{
Miri Lee ${ }^{\dagger}$, Jee-Hyun Hwang ${ }^{\dagger}$ and Kyung-Min Lim \\ College of Pharmacy, Ewha Womans University, Seoul, Korea
}

\begin{abstract}
Human eyes and skin are frequently exposed to chemicals accidentally or on purpose due to their external location. Therefore, chemicals are required to undergo the evaluation of the ocular and dermal irritancy for their safe handling and use before release into the market. Draize rabbit eye and skin irritation test developed in 1944, has been a gold standard test which was enlisted as OECD TG 404 and OECD TG 405 but it has been criticized with respect to animal welfare due to invasive and cruel procedure. To replace it, diverse alternatives have been developed: (i) For Draize eye irritation test, organotypic assay, in vitro cytotoxicity-based method, in chemico tests, in silico prediction model, and 3D reconstructed human cornealike epithelium (RhCE); (ii) For Draize skin irritation test, in vitro cytotoxicity-based cell model, and 3D reconstructed human epidermis models (RhE). Of these, RhCE and RhE models are getting spotlight as a promising alternative with a wide applicability domain covering cosmetics and personal care products. In this review, we overviewed the current alternatives to Draize test with a focus on 3D human epithelium models to provide an insight into advancing and widening their utility.
\end{abstract}

Key words: Eye irritation, Skin irritation, Alternative to animal tests, 3D reconstructed human cornea-like epithelium (RhCE) models, 3D reconstructed human epithelium (RhE) models

\section{INTRODUCTION}

Chemicals can be exposed to human accidentally or intentionally, and toxicity tests of chemicals are essential to ensure human safety against chemicals. Especially there are high probabilities of ocular and dermal exposure to pharmaceuticals, cosmetics and personal care products. It is required therefore to test the ocular and dermal irritancy of chemicals whereupon, the irritancy of chemicals are classified and labeled properly according to the severity. UN GHS categorization provides a universal standard for labeling the ocular irritancy of chemicals, which categorizes

Correspondence to: Kyung-Min Lim, College of Pharmacy, Ewha Womans University, 52 Ewhayeodae-gil, Seodaemun-gu, Seoul 03760, Korea

E-mail: kmlim@ewha.ac.kr

${ }^{\dagger}$ These authors contribute equally to this work.

This is an Open-Access article distributed under the terms of the Creative Commons Attribution Non-Commercial License (http:// creativecommons.org/licenses/by-nc/3.0) which permits unrestricted non-commercial use, distribution, and reproduction in any medium, provided the original work is properly cited. chemicals into Category 1, Category $2 \mathrm{~A} / 2 \mathrm{~B}$ and No category, and the dermal irritancy of chemicals are categorized into Category 1A/1B/1C, Category 2, Category 3, and No category according to the severity and irreversibility of irritation (1). To obtain relevant information for labeling and classification, eye and skin irritation tests are mandatory. Before 2009, Draize in vivo rabbit irritation test developed in 1940, has been only officially accepted test method by OECD (2). Draize rabbit test procedure is composed of forced application of test substance to the eye or skin of a non-anesthetized rabbit in a restrainer and subsequent scoring of signs of irritation including redness, swelling, cloudiness, edema, hemorrhage, and discharge (3). Due to this cruel and invasive procedure, experimental animals are imposed severe pain and discomfort $(4,5)$. As the concern for animal welfare increases throughout the world, the testing of finished cosmetics on animals has been banned in EU since 2004 and it enters full into force in 2013. Here, we present an overview of several types of alternatives to Draize test, with a focus on $3 \mathrm{D}$ reconstructed human cornea-like epithelium (RhCE) and 3D reconstructed human epithelium (RhE) models and suggest future direction for 
advancing 3D RhCE and RhE models.

\section{DRAIZE RABBIT EYE AND SKIN IRRITATION TEST}

In 1944, John H. Draize and his colleagues, toxicologists of US Food and Drug Administration (FDA), developed Draize rabbit irritation tests for identifying and evaluating toxic reactions when test materials are in contact with the skin, penis, and eyes (6). Draize test was originally used for evaluating the safety of cosmetics and then further extended to insecticides, sunscreens and antiseptics (7). As Draize test has been used for many types of chemicals, this test held its place as a reliable (8) and internationally accepted standard for eye and skin irritation (2) for long time.

Draize eye irritation test observes changes of cornea, conjunctiva, and iris in rabbit eye ball following the exposure to test substances (6). New Zealand White rabbit is commonly used as the test strain of choice due to its large eyes, easiness to handle and relatively cheap price (3). For one test substance, 6 rabbits are needed at maximum but it can be reduced to 3 when severe ocular damage occurs. Depending on the physical state of test substances (liquid, ointment, paste, or solid), $0.1 \mathrm{~mL}$ or $0.1 \mathrm{~g}$ of chemical is applied on the cornea and conjunctival sac of one eyeball of a conscious rabbit while the other eyeball remains untreated for the negative and paired control. Signs of ocular irritation including redness, swelling, cloudiness, edema, hemorrhage, are recorded and scored to evaluate the ocular irritancy at 1 , 2, 24, 48, and $72 \mathrm{hr}$ after exposure (if necessary, up to 21 day) and humanely euthanized (3). Although there are several scoring systems for Draize test, Maximum Average Score (MAS) is most widely used. The eye is examined at the selected time intervals after exposure and any injuries and change of the cornea, conjunctiva, and the iris are scored. MAS is 110 which comprises of the scores of cornea, 80, conjunctiva, 20 and iris, $10(3,9)$.

Skin irritation test is conducted with albino rabbits one day after the dorsum is shaved. Test substance $(0.5 \mathrm{~g}$ solid or $0.5 \mathrm{~mL}$ liquid $)$ is applied on the small area $\left(\sim 6 \mathrm{~cm}^{2}\right)$, and then the treated site is covered with a patch. Patch is removed after $4 \mathrm{hr}$ and then, signs of erythema and edema, and the responses are scored at 1, 24, 48 and $72 \mathrm{hr}$. For the initial test, in one animal is used and the test site is examined immediately after the patch has been removed. If the test substance is not corrosive, then confirmatory test is conducted with additional 2 animals. Erythema and edema are scored with grades from 0 to 4 depending on the severity. Histopathological examination should be considered to clarify equivocal responses $(10,11)$. Depending on the severity and reversibility, skin corrosion and irritation is categorized into $1 \mathrm{~A}, 1 \mathrm{~B}, 1 \mathrm{C}$ (corrosive), 2 (irritant, mean scores of 2.3 4.0 for erythema or for edema in at least 2 of 3 tested animals) and 3 (mild irritant, mean scores of 1.5 2.3 for erythema or for edema in at least 2 of 3 tested animals) (12).
Draize skin and eye irritation test has been criticized due to a large variation in the test results and species-difference between human and rabbit $(13,14)$. Moreover, this test imposes on the rabbit severe pain during the test procedure. To reduce suffering of animals from test chemicals in eye irritation, low-volume eye-irritation test (LVET), a refined version of Draize test, was developed. LVET applies lower volume $(0.01 \mathrm{~mL} / 0.01 \mathrm{~g})$ of test substances only on cornea without forced eyelid closure. Actually, LVET exhibits a higher correlation with human eye responses than original test. For skin irritation, parameters alternative to erythema and edema have also been developed such as the assessment of cutaneous blood flow, measurement of skin temperature, and skin thickness. Open application of substances was also tried to replace occluded and semi-occluded patch systems (15) but, this test still uses animals.

\section{ALTERNATIVES TO DRAIZE RABBIT EYE IRRITATION TEST}

\section{Organotypic models.}

- Ex vivo ocular organotypic models: Ocular organotypic models use fresh isolated organs (eyeball, corneas) from bovine, porcine, chicken or rabbit from slaughterhouses or after euthanasia to avoid sacrificing animals only for the eye irritation test. In isolated rabbit eye test (IRE test) (16), a whole eyeball of rabbit extracted from the dead animal is loaded into a perfusion chamber and the irritation of the test substance is evaluated by measuring swelling and scoring of corneal opacity, the area of corneal involvement, and fluorescein penetration $(17,18)$. IRE test addresses primarily the irritation or corrosion to the corneal surface as similar as the in vivo Draize rabbit eye irritation test. The extent of penetration to the corneal surface by an irritant or corrosive can be evaluated in IRE, which is not amenable in in vivo test. The primary shortcoming of the IRE test method as compared to in vivo is that the isolated eye is devoid of tear film, blood flow and nerve activities. The lack of protective barrier of tear film may result in higher false positive rates (19). In addition, iridal damage from inflammatory or neuromuscular components cannot be assessed and the conjunctival tissue is absent in the isolated eye. However, in the Draize test, the corneal score is weighted to represent major portion of ocular irritancy, accounting for $73 \%$ of the total score (The iris is $9 \%$ and the conjunctiva, 18\%). Therefore the performance of IRE may be not compromised compared to in vivo.

Although IRE test does not use live animals, it still needs to sacrifice experimental animals. To supplement this limitation, other organotypic tests were developed using organs of slaughtered animals (cow, chicken, pig). Isolated chicken eye (ICE) test employing enucleated chicken eyes obtained from an abattoir was proved to be a valuable and practical alternative to IRE (20). ICE was developed based on IRE 
and it was formally approved as OECD TG 438 in 2009 and revised in 2013 (21). ICE is composed of applying test substance $(30 \mu \mathrm{L}$ or $30 \mathrm{mg}$ ) to the ICE for $10 \mathrm{~s}$ and scoring of the corneal opacity, thickness and fluorescein staining at 30, $75,120,180$ and $240 \mathrm{~min}$. It is easy to get chicken of the same strain, age and weight, and the availability and quality of chicken eyes are good (20). But, surfactants and alcohols often result in false negative and false positives, respectively in ICE (22).

Bovine corneal opacity and permeability (BCOP, OECD TG 437) uses isolated cornea of slaughtered cow. Corneas with a horizontal diameter $<28.5 \mathrm{~mm}$ and thickness $<900 \mu \mathrm{m}$ are generally obtained from cows less than five years old (23) The OECD TG 437 recommends the use of eyes from cattle 6 to 12 months of age because the use of corneas from young animals (i.e., 6 to 12 month old) has some advantages, such as increased availability, a narrow age range, and lower risks involving exposure to bovine spongiform encephalopathy. Freshly isolated cornea is mounted horizontally in a holder which is placed inside a specially modified opacitometer. The test chemical is applied to the epithelial surface of the mounted cornea. Two different treatment protocols are used, one for liquids and sur-factants (both solids and liquids) for $10 \mathrm{~min}$, and one for nonsurfactant solids for $4 \mathrm{hr}$. Decision points are corneal opacity measured quantitatively as the amount of light transmission through the cornea, and permeability as the amount of sodium fluorescein dye passing across the full thickness of the cornea, as detected in the medium in the posterior chamber (24). BCOP test is suitable to screen out the moderate, severe and very severe eye irritants since the depth of injury can be measured. However, mild irritancy is not appropriate for BCOP with the standard protocol. Histology can aid further discrimination of mild irritants but it has not been fully validated. There is a tendency to underestimate the irritancy of substances affecting mainly the iris or the conjunctiva (25).

- Ex vivo non-ocular organotypic models: Ex vivo ocular organotypic models also lack in, or do not address conjunctival and iridial responses, inflammation and corneal recovery or reversibility of lesions (26). To address these issues, eye irritation tests using fertilized eggs of hens have been suggested that include HET-CAM (hen's egg test-chorioallantoic membrane), CAM-TB (Trypan Blue) and CAMVA. These methods use the chorioallantoic membrane which resembles the vascular mucosal tissues of human eyes and they can examine the effects of test substances on conjunctiva $(5,27)$. HET-CAM examines the hemorrhage, lysis and coagulation on the chorioallantoic membrane at the 9th day of fertilization when nerve tissue and pain perception are yet to develop. The reaction time method, in which the time until each of 3 endpoints appears, is commonly used. Another way is the irritation threshold method, which estimates the threshold concentration of the test material for these parameters. HET-CAM exhibits good correlation with Draize eye test for mild to non-irritating test materials that include surfactants $(28,29)$. However, solid and insoluble or sticky materials may be problematic in obtaining the reproducibility. In addition, pigments and dyes may cause interference (30).

HET-CAM is a rapid, cheap and efficient test method but the scoring system lacks objectivity and quantitability $(31,32)$. Hagino et al. of Shiseido Co, developed an objective evaluation tool for the CAM assay by employing trypan blue staining (CAM-TB) (33). The CAM-TB assay adopts trypan blue uptake to indicate chorioallantoic membrane injury, which showed a good correlation with the in vivo eye test $(30,33-35)$. However, since fertilized eggs eventually become chicken, HET-CAM test practically requires the sacrifice of animals.

\section{In chemico assay.}

- Hemoglobin denaturation (HD) test: Multiple mechanisms are involved in the manifestation of ocular irritation. The results of the Draize test can be explained mostly by the protein denaturation and cellular plasma membrane destruction (36) that results in corneal opacity $(37,38)$. To recapitulate the protein denaturation by chemicals, several alternative methods have been developed. The hemoglobin denaturation (HD) test can predict the eye irritation potential of chemicals by assessing the surfactant-induced denaturation of hemoglobin as can be determined by the alteration in optical properties (39).

HD was evaluated by measuring the optical density at $418 \mathrm{~nm}$ (OD418) and the shift of maximum absorption wavelength. By the comparison with a positive control $(0.1 \%$ cetylpyridinium chloride), three indices are measured: the concentration of test substance that induces $50 \%$ of the HD of the positive control (relative denaturation concentration $50 \%$, RDC50), the relative HD induced by $1 \%$ of the test substance concentration (relative denaturation rate by $1 \%, 1 \% \mathrm{RDR}$ ) and the shift in the maximal absorption wavelength caused by $1 \%$ of the test substance concentration (1\% lmax). The third index, $1 \%$ lmax, was employed to assess water-insoluble test substances since the adsorption of hemoglobin to water-insoluble particles affect absorption spectrum.

- Ocular Irritection test: The Ocular Irritection ${ }^{\circledR}$ assay, a upgraded version of Eytex ${ }^{\circledR}$ method, evaluates the ocular irritancy of test chemicals by assessing the denaturation of corneal proteins (40). The Ocular Irritection ${ }^{\circledR}$ assay can identify chemicals inducing serious eye damage (Category 1) and non-irritants (No category). The Ocular Irritection ${ }^{\circledR}$ consists of a reagent solution composed of a mixture of proteins, glycoproteins, carbohydrates, lipids and low molecular weight components that mimics the highly ordered structure of the transparent cornea, and a membrane disc controlling the access of the test material to the reagent 
solution. Irritants induce the denaturation and disaggregation of the protein reagent that can be quantified by measuring OD405. The ocular irritancy potential of a test substance is expressed as an Irritection Draize Equivalent (IDE) score (40). The scores are obtained through establishing a standard curve with a set of calibration substances with welldocumented irritancy potential.

In silico models. In silico models are computer-based methods to predict ocular irritancy of materials reliant on the previously obtained dataset of in vivo results (41). In silico models have algorithm to predict the toxicity of materials based on the relationship between physicochemical properties and bioactivity. Currently the cosmetics and pharmaceutical industry are working on in silico methods especially for eye irritation, genotoxicity/mutageniticy, skin sensitization and systemic toxicity $(42,43)$. Verma et al., developed an in silico system to identify ocular irritancy of cosmetic ingredients depending on 5 physicochemical properties; molecular weight, hydrophobicity, number of hydrogen bond donors and acceptors, and polarizability (43). In silico models do not use laboratory animals or tissues, and cost and time to get results are low compared to other alternatives (44). Additionally, as the technology and power of computer is being advanced, in silico models can employ more sophisticated software to predict eye irritancy (45). However, in silico methods need high quality datasets and large data to establish and may produce inaccurate data depending on the datasets (44).

Cell based assay. Cell based assays are inexpensive and generally are composed of simple and short procedures. There are two approaches to evaluate eye irritation using monolayer cell cultures. One is to assess changes of cell function such as fluorescein leakage test (46), cytosensor-microphysiometer test (47) and the other is to measure cytotoxicity like short time exposure test (48), neutral red uptake assay (49), red blood cell hemolysis assay (50) and HCE-T (a transfected human corneal epithelial cell line) cytotoxicity assay (51).

- Cell function based test: Fluorescein leakage (FL) test recapitulates the loss of function of tight junction in human cornea epithelium. One of critical functions of human cornea epithelium is to form an impermeable barrier to exogenously exposed materials. If the integrity of tight junction in cornea epithelium is damaged, barrier function becomes compromised, allowing the penetration of toxic substances and ultimately leading to eye irritation. Based on this mechanism, in FL test, Madin-Derby canine kidney (MDCK) cells are cultured on a permeable insert until a tight junction is formed. A test chemical is treated to the upper part of the insert for $1 \mathrm{~min}$ and then damage to tight junction in monolayer of MDCK cells is checked by measuring the extent of fluorescein dye leakage. When FL exceeds $20 \%$ of untreated control, the test chemical is considered to cause serious eye damage (Category 1, GHS). FL test is suitable for severe irritants that are water-soluble (46). But mild to moderate eye irritants require additional test to classify and colored, viscous, strong acids and bases are not applicable for FL test (46).

Cytosensor microphysiometer (CM) test uses a machine measuring cellular metabolism which reflects eye irritancy (47). Living cells have energy metabolism system using ATP. When a test substance perturbs ATP metabolism, protons are released into extracellular space which causes extracellular $\mathrm{pH}$ changes. Based on this principle, adherent cells (mouse L929 fibroblasts) are cultured on an insert with a porous membrane and after chemical is treated, $\mathrm{pH}$ changes in the medium are automatically measured by $\mathrm{CM}$. The concentration reducing the metabolic rate, $\mathrm{pH}$, to $50 \%$ of its basal rate, MRD50, is determined from three different runs. CM is applicable to water soluble substances and mixtures (52). With down approach for identification of severe irritants, MRD50 $\leq 2 \mathrm{mg} / \mathrm{mL}$ is considered as Category 1 (severe irritants) and MRD50>2 $\mathrm{mg} / \mathrm{mL}$ means No perdition can be made. At bottom up approach for identification of non-irritants, MRD50 $>80 \mathrm{mg} / \mathrm{mL}$ or $\leq 80 \mathrm{mg} / \mathrm{mL}$ means 'N/A (Not applicable for the particular classification and labelling system), MRD50>10 mg/mL means Not Classified, and MRD50 $\leq 10 \mathrm{mg} / \mathrm{mL}$ means No prediction can be made.

- Cytotoxicity based assay: Short-time exposure (STE) test determines eye irritation using a rabbit cornea cells (SIRC, Statens Seruminstitut Rabbit Cornea) with a cytotoxicity endpoint $(48,53-55)$ (OECD TG 491). SIRC cells are seeded on 96 well plate, and $5 \%$ and $0.05 \%$ of test chemicals dissolved in physiological saline or 5\% DMSO in saline or mineral oil, are exposed for $5 \mathrm{~min}$ at room temperature. After treatment, cytotoxicity is measured with MTT assay. If the cell viability is $\leq 70 \%$ at both 0.5 and $5 \%$ concentration, then the chemical is classified as Category 1. If cell viability is $\geq 70 \%$ at both concentrations, it is classified as No category (55). STE test is useful for identifying severe irritants and non-irritant but not recommended for Category 2.

- Other cytotoxicity tests: Neutral red uptake (NRU) assay is one of the most commonly used cytotoxicity tests (56). Live cells uptake neutral red into their lysosomes. When cells begin to die, the capacity to uptake neutral red is reduced. Because neutral red is red-colored, the optical density could be measured at $540 \mathrm{~nm}$ after washing step which represents the cell viability. NRU assay can use diverse cell lines, that include Chinese hamster V79 (57), $\mathrm{CHO}, 3 \mathrm{~T} 3$, and rabbit corneal cells like SIRC (58). This test is especially useful to evaluate products with low eye irritation potential and surfactants $(5,59)$.

3-(4,5-Dimethylthiazol-2-yl)-2,5-diphenyltetrazolium bromide (MTT)-type cytotoxicity tests like MTT, (4-[3-(4- 
Table 1. Comparison of methods of the RhCE models

\begin{tabular}{|c|c|c|c|c|c|c|c|}
\hline RhCE model & $\begin{array}{l}\text { Type of } \\
\text { material }\end{array}$ & $\begin{array}{c}\text { Amount of } \\
\text { treatment }\end{array}$ & $\begin{array}{l}\text { Treatment } \\
\text { time }\end{array}$ & Wash & Post-soak & Post-incubation & End point \\
\hline \multirow{2}{*}{$\begin{array}{c}\text { HCE model } \\
\text { (SkinEthic, France) }\end{array}$} & Liquid & $30 \mu \mathrm{L}$ & $30 \mathrm{~min}$ & $10 \mathrm{~mL}$ of PBS at least 2 times & $30 \mathrm{~min}$ & $30 \mathrm{~min}$ & \multirow{2}{*}{ MTT } \\
\hline & Solid & $30 \mathrm{mg}$ & $240 \mathrm{~min}$ & $25 \mathrm{~mL}$ of $\mathrm{PBS}$ & $30 \mathrm{~min}$ & $18 \mathrm{hr}$ & \\
\hline \multirow{2}{*}{$\begin{array}{c}\text { EpiOcular }^{\mathrm{TM}} \\
\text { (MatTek, USA) }\end{array}$} & Liquid & $50 \mu \mathrm{L}$ & $30 \mathrm{~min}$ & \multirow{2}{*}{$\begin{array}{l}3 \text { times in washing bottle } \\
\text { with PBS }\end{array}$} & $12 \mathrm{~min}$ & $2 \mathrm{~h}$ & \multirow{2}{*}{ MTT } \\
\hline & Solid & $50 \mathrm{mg}$ & $360 \mathrm{~min}$ & & $25 \mathrm{~min}$ & $18 \mathrm{~h}$ & \\
\hline \multirow{2}{*}{$\begin{array}{l}\text { Cornea model } \\
\text { (J-TEC, Japan) }\end{array}$} & Liquid & $50 \mu \mathrm{L}$ & $1 \mathrm{~min}$ & \multirow{2}{*}{$\begin{array}{l}\text { more than } 10 \text { times in wash- } \\
\text { ing bottle }\end{array}$} & - & $24 \mathrm{~h}$ & \multirow{2}{*}{ WST-8 } \\
\hline & Solid & $50 \mathrm{mg}$ & $24 \mathrm{hr}$ & & - & - & \\
\hline \multirow[b]{2}{*}{$\begin{array}{c}\text { MCTT HCE } \\
\text { (Biosolution, Korea) }\end{array}$} & Liquid & $40 \mu \mathrm{L}$ & $10 \mathrm{~min}$ & 4 time with PBS & - & & \multirow[b]{2}{*}{ WST-1 } \\
\hline & Solid & $40 \mathrm{mg}$ & $\begin{array}{c}60 \mathrm{~min} \\
\text { (Protocol 1.4) }\end{array}$ & $\begin{array}{l}4 \text { times with } 10 \mathrm{~mL} \text { of PBS } \\
\text { and shaking in } 30 \mathrm{~mL} \text { of PBS } \\
\text { in the beaker }\end{array}$ & - & $16 \mathrm{~h}$ & \\
\hline
\end{tabular}

- Indicates not described in the protocol.

iodophenyl)-2-(4-nitrophenyl)-2H-5-tetrazolio]-1,3-benzene disulfonage) (WST-1), (3-(4,5-dimethylthiazol-2-yl)-5-(3carboxymethoxyphenyl)-2-(4-sulfophenyl)-2H-tetrazolium) (MTS) assays are also widely used to measure cytotoxicity along with various cornea epithelium-like cell lines $(51,58)$. Interestingly, red blood cell hemolysis test uses red blood cells which have their own color. If irritants damage red blood cell (RBC) plasma membranes, it causes hemolysis. In comparison with other cytotoxicity tests, RBC hemolysis test is clear and simple and mammalian RBC is easy to get. But so far, this test has not been validated other than for surfactants (60).

Reconstructed human Cornea-like Epithelium (RhCE). Organotypic and cell based test methods lack in compatibility to the real human eyes. Interspecies differences caused by using animal eyes might lead to over- and under-prediction of ocular irritancy. Monolayer cell cultures used in cell based tests do not reflect a complex three-dimensional microenvironment of real tissues. The artificially rigid and flat surfaces of culture ware can alter cell metabolism and inherent functionality (61).

To overcome these errors, 3D human cornea equivalent models has developed. Human cornea consists of epithelium, stroma, and endothelium. Although ideal 3D human cornea equivalent models shall have all three parts of cornea but until now, only reconstructed human cornea-like epithelium (RhCE) has been developed probably due to the technical limitation. However, the corneal epithelium is the most important part to determine ocular irritancy because it is located on the outermost layer of the cornea that protects the underlying tissue by excluding foreign material. There are several RhCE models used for evaluating ocular irritancy which include EpiOcular ${ }^{\mathrm{TM}}$, SkinEthic HCE, Labcyte Cornea model and MCTT $\mathrm{HCE}^{\mathrm{TM}}$.

Generally, a test material is treated on RhCE models for certain period and the exposed tissue is washed through several steps to remove remaining test materials. RhCE models then allow the recovery from primary irritation through post incubation steps and their viability is assessed afterwards. Based on viability, the ocular irritancy of teat materials is evaluated. Detailed methods for the RhCE models are shown in Table 1.

- EpiOcular ${ }^{T M}$ (MatTek, Ashland, MA, USA): MatTek Corporation developed a commercially available 3D corneal epithelial model with primary human epidermal keratinocytes (62-64). The keratinocytes are grown on cell-culture inserts in serum-free media, to form a stratified, squamous epithelium, EpiOcular ${ }^{\mathrm{TM}}$. EpiOcular ${ }^{\mathrm{TM}}$ has been approved as the first validated reference model for RhCE-based ocular irritation test by OECD.

EpiOcular ${ }^{\mathrm{TM}}$ method is the same both for liquids and solid materials except for the timing of steps which are treatment (30 min for liquids and $6 \mathrm{hr}$ for solids), post-soak (12 min for liquids and $25 \mathrm{~min}$ for solids), and post-incubation ( $2 \mathrm{hr}$ for liquids and $18 \mathrm{hr}$ for solids). EpiOcular ${ }^{\mathrm{TM}}$ exhibits an overall accuracy of $80 \%$, sensitivity of $96 \%$, false negative rate of $4 \%$, specificity of $63 \%$ and false positive rate of $37 \%$ (65). EpiOcular ${ }^{\mathrm{TM}}$ has morphology and characteristics close to human cornea but a certain degree of difference from intact human cornea could not be ruled out since it uses keratinocyte which is non-corneal cells (66). Furthermore, EpiOcular ${ }^{\mathrm{TM}}$ is overly sensitive to the alcohol and esters (67) and highly volatile liquids, organic solvents, and certain classes of reactive chemicals (e.g., peroxides) may not be appropriate.

- HCE model (SkinEthic, Lyon, France): The Skinethic HCE model is prepared with immortalized human corneal epithelial cells (HCE) (68). The resulting tissue forms a multilayered, stratified epithelium with an overall thickness of $60 \mathrm{~mm}$, similar to normal human corneal epithelium (69). Intermediate filaments, desmosomal and hemidesmo- 
somal junctions were found as well as cytokeratin-3, the cornea-specific differentiation marker (69).

Various test protocols using the SkinEthic ${ }^{\mathrm{TM}}$ HCE model have been evaluated to improve the predictive capacity. Previously, the SkinEthic ${ }^{\mathrm{TM}}$ HCE test method was separated into two treatment protocols; a 10 min with no post-incubation (SE) or a $1 \mathrm{hr}$ with a post-treatment incubation of $16 \mathrm{hr}$ (LE) depending on the result of Eye Peptide Reactivity Assay which is used to differentiate test substances into reactive chemicals - SE or non-reactive chemicals - LE (70). However, the protocols failed to meet the acceptance criteria for predictive capacity (71). To improve the predictive capacity, the SkinEthic ${ }^{\mathrm{TM}}$ HCE test method was revised into two independent methods for liquids and solids. For the Eye Irritation Testing of Liquids (EITL protocol), substances were treated for $30 \mathrm{~min}$ and then soaked in immersion media for $30 \mathrm{~min}$ and incubated for $30 \mathrm{~min}$ (72). Eye Irritation Testing of Solids (EITS protocol) adopts $4 \mathrm{hr}$ treatment, and $18 \mathrm{hr}$ post-incubation time (72). EITL and EITS exhibit the accuracy of $84.8 \%$ and $84.4 \%$, specificity of $69.4 \%$ and $76.6 \%$, and sensitivity of $98.3 \%$ and $92.2 \%$, respectively $(71,72)$. SkinEthic ${ }^{\mathrm{TM}}$ HCE employs immortalized cell lines and difference from intact human cornea may exist (66).

- Labcyte Cornea-Model (J-TEC, Aichi, Japan): Labcyte Cornea-Model was developed by Japan Tissue Engineering Co., Ltd. (Gamagori, Aichi, Japan) using normal human cornea epithelial cells. The LabCyte Cornea-Model is similar to human corneal epithelium in the aspects of morphology, histology and marker expression (73). The expressions of corneal epithelial marker (cytokeratin 3), mucins (mucin1 and mucin-16), cell adhesion molecules (E-cadherin, claudin-1, and desmoglein-3) and basement membrane constituents (laminin 332) is observed as seen in a human corneal epithelium.

Labcyte Cornea model method has exposure, rinse, postincubation, viability measure steps like other RhCE methods, but post-incubation step is absent for the test of solid materials (74). Viability of the tissues is measured with a water-soluble formazan dye, WST-8 assay with cut-off value of $50 \%$.

- MCTT HCE ${ }^{T M}$ (Biosolution incorp, Seoul, Korea): MCTT $\mathrm{HCE}^{\mathrm{TM}}$ (Biosolution incorp) is prepared with primary human limbal epithelial cells isolated from human limbal tissues remaining after corneal transplantation. This model uses primary human corneal cells and has human cornea-like structure, namely, 3 differentiated layers; basal cell layer, wing cell layer and superficial squamous cells layer. The biomarkers of cornea such as CD44v6 and MUC1 are expressed (66). MTT HCE ${ }^{\mathrm{TM}}$ model also employs different treatment time (10 min for liquids and $1 \mathrm{hr}$ for solids) but the time interval is marginal enough to accommodate liquids and solids in a same run. In MCTT $\mathrm{HCE}^{\mathrm{TM}}$, viability cutoff is $45 \%$ (protocol 1.5) and measured with a water-sol- uble formazan forming dye, WST-1, which enables histological analysis in a same tissue.

\section{ALTERNATIVES TO DRAIZE RABBIT SKIN IRRITATION TEST}

Cell based assay. One of alternative methods to in vivo skin irritation test is cytotoxicity/neutral red assay using human keratinocyte. The test method measures the viability of human keratinocytes following the treatment of test materials by neutral red uptake. The dose of test substance that inhibits neutral red uptake by $50 \%$ (NR50) is used as a measure of cytotoxicity potential, which is ultimately translated into the skin irritation potential $(75,76)$. When activated by irritants, keratinocytes produce and release inflammatory mediators, especially IL- $1 \alpha$, which is employed as a secondary marker to identify irritants (77-80). Mouse embryo fibroblast $3 \mathrm{~T} 3$ cells have been also used for the determination of skin irritants (81-83).

Corrositex assay. Corrositex is a cell-free in vitro method used to identify the corrosive potential of chemicals, which is approved as OECD TG 435 (84). Corrositex employs liquid Chemical Detection System (CDS) which is sensitive to corrosive chemicals passing through a "biobarrier" made of a hydrated collagen matrix. CDS contains $\mathrm{pH}$ indicator dyes that change color upon the contact with corrosive chemicals. Test substances are directly applied to the biobarrier and the breakthrough time, the time required to pass through it, is used as a measure of the corrosive potential. Breakthrough time depends on the strength of the acid or base, the rate of diffusion of the test chemical and the rate of destruction of the biobarrier.

Reconstructed human Epithelium (RhE). RhE models may be a most advanced in vitro skin irritation test (SIT) method. Four RhE models, EpiSkin ${ }^{\mathrm{TM}}$, EpiDerm ${ }^{\mathrm{TM}}$ SIT (EPI-200), the SkinEthic ${ }^{\mathrm{TM}} \mathrm{RhE}$, and LabCyte EPI-MODEL24 SIT were accepted as OECD TG 439 (85) and Keraskin $^{\mathrm{TM}}$ was in the pre-validation stage (86). Generally RhE SIT is similar in procedure with some minor difference to optimize the predictive capacity (Table 2 ). The test chemical is applied directly to RhE model made of non-transformed primary human keratinocytes, which have been cultured to mimic the human epidermis. Chemical-induced skin irritation, manifested as erythema and edema, occurs through a series of events from the penetration of the chemicals through the stratum corneum to the injury of underlying keratinocytes and other skin cells. The injured cells may mediate inflammation, which eventually leads to the dilation and increased permeability of the endothelial cells producing the erythema and edema (87). RhE-based SIT methods address the key events in the cascade, namely cell/tissue damage (88) using cell viability as an endpoint. Tissue via- 
Table 2. Comparison of methods of the RhE models

\begin{tabular}{|c|c|c|c|c|c|c|}
\hline RhE model & $\begin{array}{l}\text { Type of } \\
\text { material }\end{array}$ & $\begin{array}{c}\text { Amount of } \\
\text { treatment }\end{array}$ & $\begin{array}{l}\text { Treatment } \\
\text { time }\end{array}$ & Wash & Post-incubation & End point \\
\hline $\begin{array}{c}\text { EpiSkin }^{\mathrm{TM}} \\
\text { (MatTek, USA) }\end{array}$ & $\begin{array}{l}\text { Liquid } \\
\text { Solid }\end{array}$ & $\begin{array}{l}16 \mu \mathrm{L} \\
16 \mathrm{mg}\end{array}$ & $42 \mathrm{~min}$ & $\begin{array}{l}1 \mathrm{~mL} \text { of PBS } 25 \text { times using a multistep } \\
\text { pipette }\end{array}$ & $42 \mathrm{hr}$ & MTT \\
\hline $\begin{array}{c}\text { EpiDerm }^{\mathrm{TM}} \\
\text { (MatTek, USA) }\end{array}$ & $\begin{array}{l}\text { Liquid } \\
\text { Solid }\end{array}$ & $\begin{array}{l}30 \mu \mathrm{L} \\
25 \mathrm{mg}\end{array}$ & $60 \mathrm{~min}$ & $\begin{array}{l}15 \text { times in a soft stream of PBS from a } \\
\text { washing bottle }\end{array}$ & $42 \mathrm{hr}$ & MTT \\
\hline $\begin{array}{c}\text { SkinEthic } \\
\text { (SkinEthic, France) }\end{array}$ & $\begin{array}{l}\text { Liquid } \\
\text { Solid }\end{array}$ & $\begin{array}{l}40 \mu \mathrm{L} \\
20 \mathrm{mg}\end{array}$ & $42 \mathrm{~min}$ & $\begin{array}{l}20 \text { times or more in a soft stream of PBS } \\
\text { from a washing bottle }\end{array}$ & $42 \mathrm{hr}$ & MTT \\
\hline $\begin{array}{l}\text { Labcyte EpiModel } 24 \\
\text { (J-TEC, Japan) }\end{array}$ & $\begin{array}{l}\text { Liquid } \\
\text { Solid }\end{array}$ & $\begin{array}{l}25 \mu \mathrm{L} \\
25 \mathrm{mg}\end{array}$ & $15 \mathrm{~min}$ & $\begin{array}{l}15 \text { times or more in a soft stream of PBS } \\
\text { from a washing bottle }\end{array}$ & $42 \mathrm{hr}$ & MTT \\
\hline $\begin{array}{c}\text { Keraskin }^{\mathrm{TM}} \\
\text { (Biosolution, Korea) }\end{array}$ & $\begin{array}{l}\text { Liquid } \\
\text { Solid }\end{array}$ & $\begin{array}{l}30 \mu \mathrm{L} \\
30 \mathrm{mg}\end{array}$ & $45 \mathrm{~min}$ & 4 steps with PBS & $42 \mathrm{hr}$ & MTT \\
\hline
\end{tabular}

bility in RhE models is evaluated by MTT [3-(4,5-Dimethylthiazol-2-yl)-2,5-diphenyltetrazolium bromide, Thiazolyl blue; CAS number 298-93-1] assay, which is based on the enzymatic reduction of tetrazolium into formazan dye in viable cells (87). Irritant chemicals are identified by measuring the decrease in cell viability below cutoff level (89).

- EpiSkin ${ }^{T M}$ (EpiSkin, Lyon, France): EpiSkin $^{\mathrm{TM}}$ is constructed with adult human-derived epidermal keratinocytes cultured on a dermal substitute consisting of a collagen type I matrix coated with type IV collagen. EpiSkin ${ }^{\mathrm{TM}}$ is obtained by 13-day culture (90) and for SIT, a test substance is applied topically for $15 \mathrm{~min}$ at room temperature followed by rinsing with PBS. The tissue is then post-incubated at $37^{\circ} \mathrm{C}$ for $42 \mathrm{hr}$. Aliquots of culture media were collected for further cytokine (IL-1 $\alpha$ ) measurements. SDS 5\% and PBS are used as positive and negative control, respectively.

- EpiDerm ${ }^{\text {TM }}$ (MatTek, Ashland, MA, USA): EpiDerm $^{\mathrm{TM}}$ (EPI-200, MatTek) (surface $0.63 \mathrm{~cm}^{2}$ ) cultured on cell culture inserts is available as kits. The EpiDerm ${ }^{\mathrm{TM}}$ SIT consists of a topical exposure of a test substance followed by a cell viability test. Cell viability is measured by MTT assay (91). Recent studies revealed that the MTT endpoint had clear advantages over endpoints like the release of IL- $1 \alpha$ in the prediction of skin irritants $(92,93)$.

- SkinEthic ${ }^{T M}$ (SkinEthic, Lyon, France): SkinEthic ${ }^{\mathrm{TM}} \mathrm{RhE}$ model consists of normal human keratinocytes cultured for 17-days on an inert $0.5 \mathrm{~cm}^{2}$ polycarbonate filter at the airliquid interface with a chemically defined growth medium (94). SIT with SkinEthic ${ }^{\mathrm{TM}}$ RhE involves topical application of test substance for 42 min followed by post-incubation of $42 \mathrm{hr}$, and the subsequent assessment of cell viability with MTT assay (95-97). A specific protocol was also developed for the testing of finished cosmetic products $(94,98)$. A cutoff value of $50 \%$ viability is applied to identify irritant from non-irritant.

- Labcyte EpiModel24 (J-TEC, Aichi, Japan): Labcyte EpiModel24 consists of normal human epidermal keratinocytes isolated from neonate foreskin. To cultivate keratino- cytes to maintain their phenotype, 3T3-J2 cells is used as a feeder layer $(99,100)$. Keratinocytes are cultured on an inert filter substrate (surface area $0.3 \mathrm{~cm}^{2}$ ) at the air-liquid interface for 13 days with medium containing 5\% fetal bovine serum (101). The tissues were pre-incubated overnight and topically exposed to the test chemicals for $15 \mathrm{~min}$ on the following day. Each three tissues serving as negative and positive controls were treated with distilled water and 5\% SLS (sodium lauryl sulphate). After post-incubated for $42 \mathrm{hr}$, the tissues were evaluated cell viability with MTT assay (85).

- Keraskin ${ }^{T M}$ (Biosolution incorp, Seoul, Korea): KeraSkin $^{\mathrm{TM}}$ model is reconstructed with primary human keratinocytes seeded on a $12 \mathrm{~mm}$ Millicell $^{\circledR}$ (Millipore, Billerica, MA, USA) which undergo 7 day submerge culture and 14 day air-liquid interface culture with 3T3 feeder layers. D-PBS and sodium dodecyl sulfate (SDS) were used as the negative and positive control, respectively. After overnight $(22 \pm 2 \mathrm{hr})$ pre-incubation, the test substance was applied on the tissues. After exposed for $45 \mathrm{~min}$, the tissues were rinsed with D-PBS. Tissues were post-incubated for $42 \mathrm{hr}$ and then evaluated viability with MTT assay (86).

\section{CURRENT STUDIES TO ADVANCE EYE AND SKIN IRRITATION TESTS WITH 3D RhCE AND 3D RhE MODELS}

Limitation of current 3D RhCE and 3D RhE models. Epithelial models are often fragile and have to be handled very carefully to avoid drying and damages. Cell detachment from the culture can lead to a misinterpretation of data (102). They are also somewhat limited in that they only emulate the epithelial layer and so cannot be used to determine the possible effects of substances that penetrate the stroma and endothelium. In addition, the reversibility of the irritation which is dependent on cell-cell interactions, namely those between the epithelium and adjoining stroma cannot be evaluated $(62,103,104)$. Moreover, systemic effects like hormone immune and neural influences cannot be addressed 
with these models.

Biomarker for eye irritation to develop various end points. The viability test may result in limited predictive capacity when used as a single and only endpoint. Especially, the cells which contribute to viability measurement exist in the basal layer of the 3D construct which may underestimate the events occurring at the superficial level (105). To complement the protocol and the predictive capacity of RhCE, biomarkers for eye irritation have been actively studied (106).

Choi et al. revealed that cornifelin (CNFN) and EGR-1 in MCTT $\mathrm{HCE}^{\mathrm{TM}}$ is increased by surfactants which are commonly used and widely known as eye irritants (107). Especially, CNFN is reported to increase in barrier-related diseases such as psoriatic skin, atopic dermatitis and mycosis fungoides (107). This suggests that increased expression of CNFN on the exposure to eye irritants might be linked with cellular adaptive responses to augment barrier function through surface cornification and to prevent further permeation of irritants (106).

Occludin which plays a regulatory and a structural function in tight junctions is suggested as an early biomarker for physical disorder and damage of cornea (108-110). It has been revealed that benzalkonium increases its gene expression in a dose-dependent manner (111). Occludin gene expression was suggested as an early in vitro sign for mild eye irritation assessment, reflecting that it may be employed as an early and predictive marker of sub-cytotoxic concentrations of irritants, providing the information on the extent of tissue damage (105).

Biomarker for skin irritation to develop various end points. In contrast to in vivo test, it is inevitable to investigate biomarkers to assess irritant responses in in vitro assays due to the absence of visible signs or symptoms. The most commonly used parameters are measurement of cell viability (e.g., MTT conversion) (112,113), and the membrane integrity (e.g., neutral red-uptake or LDH release) $(93,114)$. Through the validation study with five in vitro models using MTT conversion as a sole endpoint, the ECVAM management team concluded that cytotoxicity alone does not always produce the right prediction for irritants (115). In this context, measurement of cytokines or other biomolecules was investigated to improve the predictive capacity (87). IL-1 $\alpha$, a crucial inflammatory mediator in the skin, triggering the initiation of inflammation was considered as a promising biomarker for irritation (116). IL-1 $\alpha$ induces the production of proinflammatory cytokines like IL- 6 and IL-8 as well as IL- $1 \alpha$ in keratinocytes (117). IL-1 $\alpha$ also activates the translocation of cytoplasmatic NF- $\kappa B$ into the nucleus (118) and another transcription factor, the activating protein-1 (AP-1), which trigger the cellular responses related with irritation (119).
A skin-specific chemokine CCL27 which is responsible for the specific homing of $\mathrm{CLA}^{+}$memory T cells in inflammatory skin diseases like psoriasis, atopic or allergic contact dermatitis $(120,121)$ was investigated as a biomarker of skin irritation. The release of skin-derived anti-leukoprotease SKALP/elafin which is increased in the SDS-induced irritation, oleic acid and tape-stripping in vitro (122-124) was suggested as an excellent marker since it can easily be detected in the cell culture media (125). Another skin-specific serine protease inhibitor SERPIN B13/hurpin (126) was also considered as a marker for irritation since it is associated with psoriasis and irritation following UV irradiation (127).

\section{CONCLUSIONS}

As described above, alternatives to Draize test are actively studied to avoid the sacrifice of laboratory animals and to produce more human-relevant prediction. As described above, a large number of studies have been undertaken to find tests that replace the need for animals in skin safety testing. Actually, a few of these tests have been accepted by the regulatory authorities. Indeed, as of 2015, full categories of eye irritation can be addressed with the combination of organotypic methods like BCOP or ICE and 3D RhCE models in a frame of integrated testing strategy by topdown or bottom-up approaches. 3D RhCE and 3D RhE models constitute central step for this ITS approach and for cosmetic and toiletry, it could be used as a stand-alone assay. Moreover, 3D RhCE and 3D RhE models can be utilized for the pharmacological or pathophysiological tests and its application is expanding beyond chemical test to evaluate medical device and to study ocular and dermal diseases. Full coverage of epithelium, stromal and endothelium layer, and biomarkers for eye and skin irritation that are being currently studied will be key to overcome the shortcomings of 3D RhCE and 3D RhE models and advance forward.

\section{ACKNOWLEDGMENTS}

This research was supported by grants (13172MFDS987 and 16182MFDS522) from the Ministry of Food \& Drug Safety of Korea.

Received June 5, 2017; Revised June 13, 2017; Accepted June 14, 2017

\section{REFERENCES}

1. Winder, C., Azzi, R. and Wagner, D. (2005) The development of the globally harmonized system (GHS) of classification and labelling of hazardous chemicals. J. Hazard. Mater., 125, 2944. 
2. OECD (2002) Test No. 405: Acute Eye Irritation/Corrosion, OECD Publishing.

3. Wilhelmus, K.R. (2001) The Draize eye test. Surv. Ophthalmol., 45, 493-515.

4. York, M. and Steiling, W. (1998) A critical review of the assessment of eye irritation potential using the Draize rabbit eye test. J. Appl. Toxicol., 18, 233-240.

5. Christian, M.S. and Diener, R.M. (1996) Soaps and detergents: alternatives to animal eye irritation tests. Int. J. Toxicol., 15, 1-44.

6. Draize, J.H., Woodard, G. and Calvery, H.O. (1944) Methods for the study of irritation and toxicity of substances applied topically to the skin and mucous membranes. J. Pharmacol. Exp. Ther., 82, 377-390.

7. Fitzhugh, O. and Woodard, G. (1946) The toxicities of compounds related to 2,3-dimercaptopropanol (BAL) with a note on their relative therapeutic efficiency. J. Pharmacol. Exp. Ther, 87, 23-27.

8. Kay, J. and Calandra, J. (1962) Interpretation of eye irritation tests. J. Soc. Cosmet. Chem., 13, 281-289.

9. Rohde B. (1992) In vivo eye irritation test methods in Ophthalmic Toxicology. Raven Press, New York, pp. 83-108.

10. Sekizawa, J., Yasuhara, K., Suyama, Y., Yamanaka, S., Tobe, M. and Nishimura, M. (1994) A simple method for screening assessment of skin and eye irritation. J. Toxicol. Sci., 19, 2535.

11. OECD (2015) Test No. 404: Acute Dermal Irritation/Corrosion, OECD Publishing.

12. UN (2011) United Nations Globally Harmonized System of Classification and Labelling of Chemicals (GHS).

13. Griffith, J.F., Nixon, G.A., Bruce, R.D., Reer, P.J. and Bannan, E.A. (1980) Dose-response studies with chemical irritants in the albino rabbit eye as a basis for selecting optimum testing conditions for predicting hazard to the human eye. Toxicol. Appl. Pharmacol., 55, 501-513.

14. Freeberg, F., Nixon, G., Reer, P., Weaver, J., Bruce, R., Griffith, J. and Sanders, L.W., 3rd. (1986) Human and rabbit eye responses to chemical insult. Toxicol. Sci., 7, 626-634.

15. Calvin, G. (1992) New approaches to the assessment of eye and skin irritation. Toxicol. Lett., 64-65 Spec No, 157-164.

16. Burton, A., York, M. and Lawrence, R. (1981) The in vitro assessment of severe eye irritants. Food Cosmet. Toxicol., 19, 471-480.

17. Whittle, E., Basketter, D., York, M., Kelly, L., Hall, T., McCall, J., Botham, P., Esdaile, D. and Gardner, J. (1992) Findings of an interlaboratory trial of the enucleated eye method as an alternative eye irritation test. Toxicol. Method., 2, 30-41.

18. York, M., Wilson, A. and Newsome, C. (1994) The classification of soluble silicates for eye hazard using the enucleated rabbit eye test. Toxicol. In Vitro, 8, 1265-1268.

19. Bruner, L., Evans, M., McPherson, J., Southee, J. and Williamson, P. (1998) Investigation of ingredient interactions in cosmetic formulations using isolated bovine corneas. Toxicol. In Vitro, 12, 669-690.

20. Prinsen, M. and Koëter, H. (1993) Justification of the enucleated eye test with eyes of slaughterhouse animals as an alternative to the Draize eye irritation test with rabbits. Food Chem. Toxicol., 31, 69-76.
21. OECD (2013) Test No. 438: Isolated Chicken Eye Test Method for Identifying i) Chemicals Inducing Serious Eye Damage and ii) Chemicals Not Requiring Classification for Eye Irritation or Serious Eye Damage, OECD Publishing, Paris.

22. OECD (2009) Test No. 438: Isolated Chicken Eye Test Method for Identifying i) Chemicals Inducing Serious Eye Damage and ii) Chemicals Not Requiring Classification for Eye Irritation or Serious Eye Damage, OECD Guidelines for the Testing of Chemicals, Section 4, OECD Publishing.

23. OECD (2009) Test No. 438: Isolated Chicken Eye Test Method for Identifying Ocular Corrosives and Severe Irritants, OECD Publishing.

24. Gautheron, P., Dukik, M., Alix, D. and Sina, J.F. (1992) Bovine corneal opacity and permeability test: an in vitro assay of ocular irritancy. Toxicol. Sci., 18, 442-449.

25. Casterton, P., Potts, L. and Klein, B. (1996) A novel approach to assessing eye irritation potential using the bovine corneal opacity and permeability assay. J. Toxicol. Cutaneous Ocul. Toxicol., 15, 147-163.

26. Guo, X., Yang, X.F., Yang, Y., Hans, R., Cai, J.H., Xue, J.Y., Tan, X.H., Xie, X.P., Xiong, X.K. and Huang, J.M. (2012) Prediction of ocular irritancy of 26 chemicals and 26 cosmetic products with isolated rabbit eye (IRE) test. Biomed. Environ. Sci., 25, 359-366.

27. Luepke, N.P. (1985) Hen's egg chorioallantoic membrane test for irritation potential. Food Chem. Toxicol., 23, 287-291.

28. Spielmann, H., Kalweit, S., Liebsch, M., Wirnsberger, T., Gerner, I., Bertram-Neis, E., Krauser, K., Kreiling, R., Miltenburger, H., Pape, W. and Steiling, W. (1993) Validation study of alternatives to the Draize eye irritation test in Germany: cytotoxicity testing and HET-CAM test with 136 industrial chemicals. Toxicol. In Vitro, 7, 505-510.

29. Steiling, W. (1994) The Hen's Egg Test on the Chorioallantoic Membrane (HET-CAM) INCITTOX n96, ECVAM DBALM. p. 18 .

30. Hagino, S., Kinoshita, S., Tani, N., Nakamura, T., Ono, N., Konishi, K., Iimura, H., Kojima, H. and Ohno, Y. (1999) Interlaboratory validation of in vitro eye irritation tests for cosmetic ingredients. (2) Chorioallantoic membrane (CAM) test. Toxicol. In Vitro, 13, 99-113.

31. Luepke, N. and Wallat, S. (1987) HET-CAM reproducibility studies in Alternative Methods in Toxicology (Vol. 5) - In Vitro Toxicology: Approaches to Validation, pp. 353-363.

32. Kalweit, S., Besoke, R., Gerner, I. and Spielmann, H. (1990) A national validation project of alternative methods to the Draize rabbit eye test. Toxicol. In Vitro, 4, 702-706.

33. Hagino, S., Itagaki, H., Kato, S., Kobayashi, T. and Tanaka, M. (1991) Quantitative evaluation to predict the eye irritancy of chemicals: modification of chorioallantoic membrane test by using trypan blue. Toxicol. In Vitro, 5, 301-304.

34. Vinardell, M. and García, L. (2000) The quantitive chlorioallantoic membrane test using trypan blue stain to predict the eye irritancy of liquid scintillation cocktails. Toxicol. In Vitro, 14, 551-555.

35. Lagarto, A., Vega, R., Guerra, I. and González, R. (2006) In vitro quantitative determination of ophthalmic irritancy by the chorioallantoic membrane test with trypan blue staining as alternative to eye irritation test. Toxicol. In Vitro, 20, 699-702. 
36. Hayashi, T., Itagaki, H., Fukuda, T., Tamura, U. and Kato, S. (1994) Multivariate factorial analysis of data obtained in seven in vitro test systems for predicting eye irritancy. Toxicol. In Vitro, 8, 215-220.

37. Gordon, V., Kelly, C. and Bergman, H. (1990) Applications of the EYTEX ${ }^{\mathrm{TM}}$ method. Toxicol. In Vitro, 4, 314-317.

38. Miyazawa, K., Ogawa, M. and Mitsui, T. (1984) The physicochemical properties and protein denaturation potential of surfactant mixtures. Int. J. Cosmet. Sci., 6, 33-46.

39. Hayashi, T., Itagaki, H., Fukuda, T., Tamura, U. and Kato, S. (1993) Quantitative evaluation for the prediction of eye irritation using hemoglobin. AATEX, 2, 25-31.

40. Eskes, C., van Vliet, E., Schäffer, M. and Zuang, V. (2014) Ocular toxicity in In Vitro Toxicology Systems. Springer, pp. 169-197.

41. Saliner, A.G., Patlewicz, G. and Worth, A.P. (2008) A review of (Q) SAR models for skin and eye irritation and corrosion. QSAR Comb. Sci., 27, 49-59.

42. Modi, S., Hughes, M., Garrow, A. and White, A. (2012) The value of in silico chemistry in the safety assessment of chemicals in the consumer goods and pharmaceutical industries. Drug Discov. Today, 17, 135-142.

43. Verma, R. and Matthews, E. (2015) An in silico expert system for the identification of eye irritants. SAR QSAR Environ. Res., 26, 383-395.

44. Valerio, L.G., Jr. (2009) In silico toxicology for the pharmaceutical sciences. Toxicol. Appl. Pharmacol., 241, 356-370.

45. Nigsch, F., Macaluso, N.M., Mitchell, J.B. and Zmuidinavicius, D. (2009) Computational toxicology: an overview of the sources of data and of modelling methods. Expert Opin. Drug Metab. Toxicol., 5, 1-14.

46. OECD (2012) Test No. 460: Fluorescein Leakage Test Method for Identifying Ocular Corrosives and Severe Irritants, OECD Publishing.

47. Harbell, J., Osborne, R., Carr, G. and Peterson, A. (1999) Assessment of the cytosensor microphysiometer assay in the COLIPA in vitro eye irritation validation study. Toxicol. In Vitro, 13, 313-323.

48. Takahashi, Y., Koike, M., Honda, H., Ito, Y., Sakaguchi, H., Suzuki, H. and Nishiyama, N. (2008) Development of the short time exposure (STE) test: an in vitro eye irritation test using SIRC cells. Toxicol. In Vitro, 22, 760-770.

49. Jones, P.A., Bracher, M., Marenus, K. and Kojima, H. (1999) Performance of the neutral red uptake assay in the COLIPA international validation study on alternatives to the rabbit eye irritation test. Toxicol. In Vitro, 13, 325-333.

50. Pape, W.J., Pfannenbecker, U. and Hoppe, U. (1987-1988) Validation of the red blood cell test system as in vitro assay for the rapid screening of irritation potential of surfactants. Mol. Toxicol., 1, 525-536.

51. Kruszewski, F., Walker, T. and DiPasquale, L. (1997) Evaluation of a human corneal epithelial cell line as an in vitro model for assessing ocular irritation. Toxicol. Sci., 36, 130-140.

52. Nash, J.R., Mun, G., Raabe, H.A. and Curren, R. (2014) Using the cytosensor microphysiometer to assess ocular toxicity. Curr. Protoc. Toxicol., 61, 1.13.1-11.

53. Kojima, H., Hayashi, K., Sakaguchi, H., Omori, T., Otoizumi, T., Sozu, T., Kuwahara, H., Hayashi, T., Sakaguchi, M., Toyoda, A., Goto, H., Watanabe, S., Ahiko, K., Nakamura, T. and Morimoto, T. (2013) Second-phase validation study of short time exposure test for assessment of eye irritation potency of chemicals. Toxicol. In Vitro, 27, 1855-1869.

54. Takahashi, Y., Hayashi, K., Abo, T., Koike, M., Sakaguchi, H. and Nishiyama, N. (2011) The Short Time Exposure (STE) test for predicting eye irritation potential: intra-laboratory reproducibility and correspondence to globally harmonized system (GHS) and EU eye irritation classification for 109 chemicals. Toxicol. In Vitro, 25, 1425-1434.

55. OECD (2015) Test No. 491: Short Time Exposure In Vitro Test Method for Identifying i) Chemicals Inducing Serious Eye Damage and ii) Chemicals Not Requiring Classification for Eye Irritation or Serious Eye Damage, OECD Publishing.

56. Borenfreund, E. and Puerner, J.A. (1985) Toxicity determined in vitro by morphological alterations and neutral red absorption. Toxicol. Lett., 24, 119-124.

57. Ikarashi, Y., Tsuchiya, T. and Nakamura, A. (1997) [Cytotoxicity of chemicals used in household products: estimation of eye irritating potency of 25 chemicals tested during 19911996]. Kokuritsu Iyakuhin Shokuhin Eisei Kenkyusho Hokoku, (115), 130-134.

58. Vian, L., Vincent, J., Maurin, J., Fabre, I., Giroux, J. and Cano, J. (1995) Comparison of three in vitro cytotoxicity assays for estimating surfactant ocular irritation. Toxicol. In Vitro, 9, 185-190.

59. Rougier, A., Cottin, M., De Silva, O., Roguet, R., Catroux, P., Toufic, A. and Dossou, K. (1991) In vitro methods: their relevance and complementarity in ocular safety assessment. Lens Eye Toxic. Res., 9, 229-245.

60. Gettings, S.D., Lordo, R.A., Hintze, K.L., Bagley, D.M., Casterton, P.L., Chudkowski, M., Curren, R.D., Demetrulias, J.L., Dipasquale, L.C., Earl, L.K., Feder, P.I., Galli, C.L., Glaza, S.M., Gordon, V.C., Janus, J., Kurtz, P.J., Marenus, K.D., Moral, J., Pape, W.J., Renskers, K.J., Rheins, L.A., Roddy, M.T., Rozen, M.G., Tedeschi, J.P. and Zyracki, J. (1996) The CTFA Evaluation of Alternatives Program: an evaluation of in vitro alternatives to the Draize primary eye irritation test. (Phase III) surfactant-based formulations. Food Chem. Toxicol., 34, 79-117.

61. Antoni, D., Burckel, H., Josset, E. and Noel, G. (2015) Threedimensional cell culture: a breakthrough in vivo. Int. J. Mol. Sci., 16, 5517-5527.

62. McLaughlin, C.R., Tsai, R., Latorre, M.A. and Griffith, M. (2009) Bioengineered corneas for transplantation and in vitro toxicology. Front. Biosci. (Landmark Ed.), 14, 3326-3337.

63. Sheasgreen, J., Klausner, M., Kandarova, H. and Ingalls, D. (2009) The MatTek story - how the three Rs principles led to 3-D tissue success! Altern. Lab. Anim., 37, 611-622.

64. Pfannenbecker, U., Bessou-Touya, S., Faller, C., Harbell, J., Jacob, T., Raabe, H., Tailhardat, M., Alépée, N., De Smedt, A., De Wever, B., Jones, P., Kaluzhny, Y., Le Varlet, B., McNamee, P., Marrec-Fairley, M. and Van Goethem, F. (2013) Cosmetics Europe multi-laboratory pre-validation of the EpiOcular $^{\mathrm{TM}}$ reconstituted human tissue test method for the prediction of eye irritation. Toxicol. In Vitro, 27, 619-626.

65. OECD (2015) Test No. 492: Reconstructed human Cornealike Epithelium (RhCE) test method for identifying chemicals not requiring classification and labelling for eye irritation or serious eye damage (OECD Ed.). OECD Publishing, Paris. 
66. Jung, K.M., Lee, S.H., Ryu, Y.H., Jang, W.H., Jung, H.S., Han, J.H., Seok, S.H., Park, J.H., Son, Y., Park, Y.H. and Lim, K.M. (2011) A new 3D reconstituted human corneal epithelium model as an alternative method for the eye irritation test. Toxicol. In Vitro, 25, 403-410.

67. Balls, M., Brantom, P., Cassidy, S., Esdaile, D., Fentem, J., Liebsch, M., McPherson, J., Pfannenbecker, U. and Prinsen, M. (1999) Preliminary evaluation of the application of reference standards in the prevalidation and validation of in vitro test for eye irritation in Alternatives to Animal Testing II, proceedings (Clark, D.G., Lisansky, S.G. and Macmillan, R. Ed.). Brussels CPL Press, Berkshire, pp. 201-204.

68. Alépée, N., Bessou-Touya, S., Cotovio, J., De Smedt, A., De Wever, B., Faller, C., Jones, P., Le Varlet, B., Marrec-Fairley, M., Pfannenbecker, U., Tailhardat, M., van Goethem, F. and McNamee, P. (2013) Cosmetics Europe multi-laboratory prevalidation of the SkinEthic ${ }^{\mathrm{TM}}$ reconstituted human corneal epithelium test method for the prediction of eye irritation. Toxicol. In Vitro, 27, 1476-1488.

69. Nguyen, D., Beuerman, R., De Wever, B. and Rosdy, M. (2003) Three-dimensional construct of the human corneal epithelium for in vitro toxicology in Alternative Toxicological Methods. CRC Press LLC, pp. 147-159.

70. Freeman, S.J., Alépée, N., Barroso, J., Cole, T., Compagnoni, A., Rubingh, C., Eskes, C., Lammers, J., McNamee, P., Pfannenbecker, U. and Zuang, V. (2010) Prospective validation study of reconstructed human tissue models for eye irritation testing. ALTEX, 27, 255-260.

71. Barroso, J., Alépée, N., Cole, T., Eskes, C., Freeman, S., Liška, R., McNamee, P., Pfannenbecker, U., Reus, A. and Rubingh, C. (2015) EURL ECVAM - Cosmetics Europe prospective validation study of Reconstructed human tissuebased test methods for serious eye damage/eye irritation testing. Poster Presented at the Congress of the European Societies of Toxicology (EUROTOX), Porto, Portugal, pp. 13-16, September, 2015.

72. Alépée, N., Leblanc, V., Adriaens, E., Grandidier, M., Lelièvre, D., Meloni, M., Nardelli, L., Roper, C., Santirocco, E., Toner, F., Van Rompay, A., Vinall, J. and Cotovio, J. (2016) Multilaboratory validation of SkinEthic HCE test method for testing serious eye damage/eye irritation using liquid chemicals. Toxicol. In Vitro, 31, 43-53.

73. Katoh, M., Uemura, N., Hamajima, F., Ogasawara, T. and Hata, K.-i. (2012) Morphological characterization of a reconstructed human corneal epithelial model (LabCyte CORNEAMODEL) as an alternative to the Draize eye test for the assessment of eye irritation. AATEX, 17, 2-8.

74. Katoh, M., Hamajima, F., Ogasawara, T. and Hata, K.-i. (2013) Establishment of a new in vitro test method for evaluation of eye irritancy using a reconstructed human corneal epithelial model, LabCyte CORNEA-MODEL. Toxicol. In Vitro, 27, 2184-2192.

75. Osborne, R. and Perkins, M. (1991) In vitro skin irritation testing with human skin cell cultures. Toxicol. In Vitro, 5, 563-567.

76. Sanchez, L., Mitjans, M., Infante, M. and Vinardell, M. (2006) Potential irritation of lysine derivative surfactants by hemolysis and $\mathrm{HaCaT}$ cell viability. Toxicol. Lett., 161, 53-60.

77. Gueniche, A. and Ponec, M. (1993) Use of human skin cell cultures for the estimation of potential skin irritants. Toxicol.
In Vitro, 7, 15-24.

78. Corsini, E., Bruccoleri, A., Marinovich, M. and Galli, C. (1996) Endogenous interleukin- $1 \alpha$ is associated with skin irritation induced by tributyltin. Toxicol. Appl. Pharmacol., 138, 268-274.

79. Martinez, V., Corsini, E., Mitjans, M., Pinazo, A. and Vinardell, M.P. (2006) Evaluation of eye and skin irritation of arginine-derivative surfactants using different in vitro endpoints as alternatives to the in vivo assays. Toxicol. Lett., 164, 259-267.

80. Roguet, R. (1999) Use of skin cell cultures for in vitro assessment of corrosion and cutaneous irritancy. Cell Biol. Toxicol., 15, 63-75.

81. Hockley, K. and Baxter, D. (1986) Use of the $3 T 3$ cell-neutral red uptake assay for irritants as an alternative to the rabbit (Draize) test. Food Chem. Toxicol., 24, 473-475.

82. Jírová, D., Kejlová, K., Brabec, M., Bendova, H. and Kolářová, H. (2003) The benefits of the 3T3 NRU test in the safety assessment of cosmetics: long-term experience from pre-marketing testing in the Czech Republic. Toxicol. In Vitro, 17, 791-796.

83. Benavides, T., Martínez, V., Mitjans, M., Infante, M.R., Moran, C., Clapés, P., Clothier, R. and Vinardell, M.P. (2004) Assessment of the potential irritation and photoirritation of novel amino acid-based surfactants by in vitro methods as alternative to the animal tests. Toxicology, 201, 87-93.

84. OECD (2014) Test No. 435: In Vitro Membrane Barrier Test Method for Skin Corrosion (OECD Ed.). OECD Publishing, Paris.

85. OECD (2013) Test No. 439: In Vitro Skin Irritation: Reconstructed Human Epidermis Test Method. OECD guidelines for the testing of chemicals (OECD Ed.). OECD Publishing, Paris.

86. Jung, K.M., Lee, S.H., Jang, W.H., Jung, H.S., Heo, Y., Park, Y.H., Bae, S., Lim, K.M. and Seok, S.H. (2014) KeraSkinVM: a novel reconstructed human epidermis model for skin irritation tests. Toxicol. In Vitro, 28, 742-750.

87. Welss, T., Basketter, D.A. and Schröder, K.R. (2004) In vitro skin irritation: facts and future. State of the art review of mechanisms and models. Toxicol. In Vitro, 18, 231-243.

88. Spielmann, H., Hoffmann, S., Liebsch, M., Botham, P., Fentem, J.H., Eskes, C., Roguet, R., Cotovio, J., Cole, T., Worth, A., Heylings, J., Jones, P., Robles, C., Kandárová, H., Gamer, A., Remmele, M., Curren, R., Raabe, H., Cockshott, A., Gerner, I. and Zuang, V. (2007) The ECVAM international validation study on in vitro tests for acute skin irritation: report on the validity of the EPISKIN and EpiDerm assays and on the skin integrity function test. Altern. Lab. Anim., 35, 559-601.

89. OECD (2013) Test No. 439: In Vitro Skin Irritation: Reconstructed Human Epidermis Test Method, OECD Publishing.

90. Tinois, E., Gaetani, Q., Gayraud, B., Dupont, D., Rougier, A. and Pouradier, D.X. (1994) The Episkin model: Successful reconstruction of human epidermis in vitro in In Vitro Skin Toxicology. Mary Ann Liebert, New York, pp. 133-140.

91. Mosmann, T. (1983) Rapid colorimetric assay for cellular growth and survival: application to proliferation and cytotoxicity assays. J. Immunol. Methods, 65, 55-63.

92. Faller, C., Bracher, M., Dami, N. and Roguet, R. (2002) Predictive ability of reconstructed human epidermis equivalents for the assessment of skin irritation of cosmetics. Toxicol. In Vitro, 16, 557-572. 
93. Faller, C. and Bracher, M. (2002) Reconstructed skin kits: reproducibility of cutaneous irritancy testing. Skin Pharmacol. Appl. Skin Physiol., 15 Suppl 1, 74-91.

94. Rosdy, M. and Clauss, L.C. (1990) Terminal epidermal differentiation of human keratinocytes grown in chemically defined medium on inert filter substrates at the air-liquid interface. J. Invest. Dermatol., 95, 409-414.

95. de Brugerolle de Fraissinette, A., Picarles, V., Chibout, S., Kolopp, M., Medina, J., Burtin, P., Ebelin, M.E., Osborne, S., Mayer, F.K., Spake, A., Rosdy, M., De Wever, B., Ettlin, R.A. and Cordier, A. (1999) Predictivity of an in vitro model for acute and chronic skin irritation (SkinEthic) applied to the testing of topical vehicles. Cell Biol. Toxicol., 15, 121135.

96. Tornier, C., Rosdy, M. and Maibach, H.I. (2006) In vitro skin irritation testing on reconstituted human epidermis: reproducibility for 50 chemicals tested with two protocols. Toxicol. In Vitro, 20, 401-416.

97. Kandárová, H., Liebsch, M., Schmidt, E., Genschow, E, Traue, D., Spielmann, H., Meyer, K., Steinhoff, C., Tornier, C., De Wever, B. and Rosdy, M. (2006) Assessment of the skin irritation potential of chemicals by using the SkinEthic reconstructed human epidermal model and the common skin irritation protocol evaluated in the ECVAM skin irritation validation study. Altern. Lab. Anim., 34, 393-406.

98. De Wever, B. and Charbonniers, V. (2002) Using tissue engineered skin to evaluate the irritation potential of skin care products. Cosmet. Toilet., 117, 28-38.

99. Green, H. (1978) Cyclic AMP in relation to proliferation of the epidermal cell: a new view. Cell, 15, 801-811.

100. Rheinwald, J. and Green, H. (1975) Serial cultivation of strains of human epidermal keratinocytes in defined clonal and serum-free culture. J. Invest. Dermatol., 6, 331-342.

101. Kojima, H., Katoh, M., Shinoda, S., Hagiwara, S., Suzuki, T., Izumi, R., Yamaguchi, Y., Nakamura, M., Kasahawa, T. and Shibai, A. (2014) A catch-up validation study of an in vitro skin irritation test method using reconstructed human epidermis LabCyte EPI-MODEL24. J. Appl. Toxicol., 34, 766-774.

102. Davila, J.C., Rodriguez, R.J., Melchert, R.B. and Acosta, D., Jr. (1998) Predictive value of in vitro model systems in toxicology. Annu. Rev. Pharmacol. Toxicol., 38, 63-96.

103. Wilson, S.E., Liu, J.J. and Mohan, R.R. (1999) Stromal-epithelial interactions in the cornea. Prog. Retin. Eye Res., 18, 293-309.

104. Wilson, S.L., Yang, Y. and El Haj, A.J. (2014) Corneal stromal cell plasticity: in vitro regulation of cell phenotype through cell-cell interactions in a three-dimensional model. Tissue Eng Part A, 20, 225-238.

105. Meloni, M., Pauly, A., De Servi, B., Le Varlet, B. and Baudouin, C. (2010) Occludin gene expression as an early in vitro sign for mild eye irritation assessment. Toxicol. In Vitro, 24, 276-285.

106. Choi, S., Lee, M., Lee, S.H., Jung, H.S., Kim, S.Y., Chung, T.Y., Choe, T.B., Chun, Y.J. and Lim, K.M. (2015) Identification of cornifelin and early growth response- 1 gene as novel biomarkers for in vitro eye irritation using a 3D reconstructed human cornea model MCTT $\mathrm{HCE}^{\mathrm{TM}}$. Arch. Toxicol., 89, 1589-1598.
107. Michibata, H., Chiba, H., Wakimoto, K., Seishima, M., Kawasaki, S., Okubo, K., Mitsui, H., Torii, H. and Imai, Y. (2004) Identification and characterization of a novel component of the cornified envelope, cornifelin. Biochem. Biophys. Res. Commun., 318, 803-813.

108. McCarthy, K.M., Skare, I.B., Stankewich, M.C., Furuse, M., Tsukita, S., Rogers, R.A., Lynch, R.D. and Schneeberger, E.E. (1996) Occludin is a functional component of the tight junction. J. Cell Sci., 109, 2287-2298.

109. Matter, K. and Balda, M.S. (2007) Epithelial tight junctions, gene expression and nucleo-junctional interplay. J. Cell Sci., 120, 1505-1511.

110. Ajani, G., Sato, N., Mack, J.A. and Maytin, E.V. (2007) Cellular responses to disruption of the permeability barrier in a three-dimensional organotypic epidermal model. Exp. Cell Res., 313, 3005-3015.

111. Pauly, A., Meloni, M., Brignole-Baudouin, F., Warnet, J.M. and Baudouin, C. (2009) Multiple endpoint analysis of the 3D-reconstituted corneal epithelium after treatment with benzalkonium chloride: early detection of toxic damage. Invest. Ophthalmol. Vis. Sci., 50, 1644-1652.

112. Gay, R., Swiderek, M., Nelson, D. and Ernesti, A. (1992) The living skin equivalent as a model in vitro for ranking the toxic potential of dermal irritants. Toxicol. In Vitro, 6, 303315.

113. Triglia, D., Sherard Braa, S., Yonan, C. and Naughton, G.K. (1991) Cytotoxicity testing using neutral red and MTT assays on a three-dimensional human skin substrate. Toxicol. In Vitro, 5, 573-578.

114. Osborne, R. and Perkins, M. (1994) An approach for development of alternative test methods based on mechanisms of skin irritation. Food Chem. Toxicol., 32, 133-142.

115. Fentem, J.H., Briggs, D., Chesné, C., Elliott, G.R., Harbell, J.W., Heylings, J.R., Portes, P., Roguet, R., van de Sandt, J.J. and Botham, P.A. (2001) A prevalidation study on in vitro tests for acute skin irritation: results and evaluation by the Management Team. Toxicol. In Vitro, 15, 57-93.

116. Coquette, A., Berna, N., Poumay, Y. and Pittelkow, M. (2000) The keratinocyte in cutaneous irritation and sensitization in Biochemical Modulation of Skin Reaction. CRC Press, New York, pp. 125-143.

117. Sims, J.E., Gayle, M.A., Slack, J.L., Alderson, M.R., Bird, T.A., Giri, J.G., Colotta, F., Re, F., Mantovani, A. and Shanebeck, K. (1993) Interleukin 1 signaling occurs exclusively via the type I receptor. Proc. Natl. Acad. Sci. U.S.A., 90, 6155-6159.

118. Stylianou, E., O’Neill, L., Rawlinson, L., Edbrooke, M., Woo, P. and Saklatvala, J. (1992) Interleukin 1 induces NF$\kappa \mathrm{B}$ through its type I but not its type II receptor in lymphocytes. J. Biol. Chem., 267, 15836-15841.

119. O’Neill, L.A. and Greene, C. (1998) Signal transduction pathways activated by the IL-1 receptor family: ancient signaling machinery in mammals, insects, and plants. J. Leukoc. Biol., 63, 650-657.

120. Morales, J., Homey, B., Vicari, A.P., Hudak, S., Oldham, E., Hedrick, J., Orozco, R., Copeland, N.G., Jenkins, N.A., McEvoy, L.M. and Zlotnik, A. (1999) CTACK, a skin-associated chemokine that preferentially attracts skin-homing memory T cells. Proc. Natl. Acad. Sci. U.S.A., 96, 14470-14475. 
121. Homey, B., Alenius, H., Müller, A., Soto, H., Bowman, E.P., Yuan, W., McEvoy, L., Lauerma, A.I., Assmann, T., Bünemann, E., Lehto, M., Wolff, H., Yen, D., Marxhausen, H., To, W., Sedgwick, J., Ruzicka, T., Lehmann, P. and Zlotnik, A. (2002) CCL27-CCR10 interactions regulate T cellmediated skin inflammation. Nat. Med., 8, 157-165.

122. Schalkwijk, J., Van Vlijmen, I., Alkemade, J. and De Jongh, G. (1993) Immunohistochemical localization of SKALP/elafin in psoriatic epidermis. J. Invest. Dermatol., 100, 390-393.

123. van Bergen, B.H., Andriessen, M.P., Spruijt, K.I., van de Kerkhof, P.C. and Schalkwijk, J. (1996) Expression of SKALP/ elafin during wound healing in human skin. Arch. Dermatol. Res., 288, 458-462.

124. Boelsma, E., Gibbs, S. and Ponec, M. (1998) Expression of skin-derived antileukoproteinase (SKALP) in reconstructed human epidermis and its value as a marker for skin irrita- tion. Acta Derm. Venereol., 78, 107-113.

125. Tanaka, N., Fujioka, A., Tajima, S., Ishibashi, A. and Hirose, S. (2000) Elafin is induced in epidermis in skin disorders with dermal neutrophilic infiltration: interleukin- $1 \beta$ and tumour necrosis factor- $\alpha$ stimulate its secretion in vitro. Br. $J$. Dermatol., 143, 728-732.

126. Abts, H.F., Welss, T., Mirmohammadsadegh, A., Köhrer, K., Michel, G. and Ruzicka, T. (1999) Cloning and characterization of hurpin (protease inhibitor 13): a new skin-specific, UV-repressible serine proteinase inhibitor of the ovalbumin serpin family. J. Mol. Biol., 293, 29-39.

127. Welss, T., Sun, J., Irving, J.A., Blum, R., Smith, A.I., Whisstock, J.C., Pike, R.N., Von Mikecz, A., Ruzicka, T., Bird, P.I. and Abts, H.F. (2003) Hurpin is a selective inhibitor of lysosomal cathepsin L and protects keratinocytes from ultraviolet-induced apoptosis. Biochemistry, 42, 7381-7389. 